DOI: $10.5216 /$ cab.v13i3.7132

\title{
COMPORTAMENTO INGESTIVO E RESPOSTAS FISIOLÓGICAS DE NOVILHOS NELORE EM DIFERENTES CONDIÇÕES DE PASTEJO
}

\author{
Cleiton Luiz Tonello ${ }^{1}$, LeONiR Bueno Ribeiro ${ }^{2}$, ORlando Rus Barbosa ${ }^{3}$, CARLA Franciele \\ HÖRING $^{1}$, MAICON CARARD $^{4}$, CARLOS EDUARDO FURTADO $^{3}$ \\ ${ }^{1}$ Pós-graduandos da Universidade Estadual de Maringá, Maringá, PR, Brasil. cleitontonello@msn.com \\ ${ }^{2}$ Zootecnista, Mestre, Brazilian Pet Foods Ltda Licensee, Arapongas, PR. Brasil \\ ${ }^{3}$ Professor Doutor da Universidade Estadual de Maringá, Maringá, PR, Brasil. \\ ${ }^{4}$ Aluno de Graduação do curso de Zootecnia da Universidade Estadual do Oeste do Paraná, Marechal Cândido Rondon, PR, Brasil.
}

Este trabalho teve o objetivo de avaliar o comportamento ingestivo e respostas fisiológicas de novilhos Nelore em diferentes condições de pastejo. Foram utilizados cinco novilhos da raça Nelore pesando em média 390,78 $\pm 14 \mathrm{~kg}$ de PV, distribuídos em cinco tratamentos experimentais: pasto limpo sem fornecimento de suplemento concentrado (PLSC), pasto sujo sem fornecimento de suplemento concentrado (PSSC), pasto limpo com fornecimento de suplemento concentrado (PLCC), pasto sujo com fornecimento de suplemento concentrado (PSCC) e livre acesso aos pastos sem fornecimento de suplemento concentrado (LAPSC). Utilizou-se delineamento experimental em quadrado latino 5 x 5 . O comportamento ingestivo dos animais foi mensurado por meio de observação visual no final de cada período experimental em intervalos de dez minutos, durante 24 horas, e as variáveis fisiológicas avaliadas foram temperatura retal, frequência respiratória e frequência cardíaca. As respostas fisiológicas dos animais não foram influenciadas pelos tratamentos. O número de passos realizados pelos animais mantidos nos tratamentos PLSC (6,08 passos/min) e PLCC (5,62 passos/min $)$ foram significativamente menores que nos tratamentos PSSC (16,84 passos/min) e PSCC (14,58 $\mathrm{passos} / \mathrm{min})$, demonstrando maior atividade de locomoção nos animais nos piquetes com invasoras.

PALAVRAS-CHAVE: frequência cardíaca; invasoras; locomoção; pastagens.

\section{INGESTIVE BEHAVIOR AND PHYSIOLOGICAL RESPONSES OF NELLORE IN DIFFERENT GRAZING CONDITIONS}

\section{ABSTRACT}

This study aimed to evaluate the ingestive behavior and physiological responses of steers under different grazing conditions. Five Nellore steers, weighing an average of $390.78 \pm 14 \mathrm{~kg} \mathrm{BW}$, were assigned to five experimental treatments: clean pasture without concentrate supplementation (PLSC), dirty pasture without concentrate supplementation (PSSC), clean pasture with concentrate supplementation (PLCC), dirty pasture with concentrate supplementation (PSCC) and free access to pasture without concentrate supplementation (LAPSC). The experimental design was a 5 x 5 Latin Square. The grazing behavior was measured through visual observation at the end of each trial in ten-minute intervals for 24 hours, and the physiological variables comprised rectal temperature, respiratory rate and heart rate. The physiological responses of animals were not affected by treatments. The number of steps performed by the animals kept in treatments PLSC (6.08 steps/min) and PLCC (5.62 steps/min) were significantly lower than those in treatments PSSC (16.84 steps/min) and PSCC (14.58 steps/min), showing increased activity of locomotion in animals in paddocks with weeds.

KEYWORDS: heart rate; locomotion; pasture; weeds. 


\section{INTRODUÇÃO}

O sistema de criação de bovinos a pasto é caracterizado por uma série de fatores e suas interações podem afetar o comportamento ingestivo dos animais, comprometendo seu desempenho e, consequentemente, a viabilidade da propriedade (PARDO et al., 2003). Segundo PALHANO et al. (2007), o consumo diário de forragem é o aspecto central para uma maior compreensão do comportamento dos animais em pastejo, diretamente influenciado por fatores relacionados à planta forrageira e ao animal.

O comportamento ingestivo dos ruminantes em pastejo pode ser caracterizado pela distribuição desuniforme de uma sucessão de períodos definidos e discretos de atividades, comumente denominados ingestão, ruminação e repouso (FISCHER et al., 2000). A capacidade de um alimento ser ingerido pelo animal depende da ação de fatores que interagem em diferentes situações de alimentação, comportamento animal e meio ambiente.

Com o estudo do comportamento ingestivo dos ruminantes, pode-se adequar práticas de manejo que venham a aumentar a produtividade, garantindo, também, melhor estado sanitário e maior longevidade aos animais (FISCHER et al., 2002). Um outro fator relevante é o auxílio prestado pelos resultados do estudo do comportamento alimentar dos ruminantes, no que se refere ao entendimento de como os animais ajustam esse comportamento em função das variações observadas no pasto e no ambiente (BRÂNCIO et al., 2003).

A produção animal em pastagem depende de fatores relacionados à planta e ao animal; portanto, a quantidade e a forma como a forragem é fornecida ao animal determina diferentes respostas no consumo e desempenho. $\mathrm{O}$ animal em pastejo está sob o efeito de muitos fatores que podem influenciar a ingestão de forragem, dentre os quais sobressai a oportunidade de selecionar a dieta, pois o pastejo seletivo permite compensar a baixa qualidade da forragem, permitindo a ingestão de partes mais nutritivas das plantas (SILVA et al., 2009). Entretanto, o comportamento seletivo promove aumento no tempo total de pastejo.

Este trabalho foi realizado com o objetivo de avaliar alterações das respostas fisiológicas e comportamentais de novilhos Nelore mantidos em diferentes condições de pastejo.

\section{MATERIAL E MÉTODOS}

O experimento foi realizado no município de Céu Azul, situado na região Oeste do estado do Paraná, localizado a uma latitude $24^{\circ} 57^{\prime} 21$ " sul e a uma longitude 5327'19" oeste. Foram utilizados cinco novilhos da raça Nelore, pesando em média $390,78 \pm 14 \mathrm{~kg}$ de PV. A área experimental foi constituída de cinco piquetes com aproximadamente um hectare cada. No período anterior ao experimento foi realizado o controle de plantas invasoras da pastagem em dois dos piquetes; em um piquete foi realizado controle parcial das invasoras, permitindo à infestação em metade da área experimental e em dois piquetes não foi realizado controle.

Os animais foram mantidos em pastagem nativa, com predominância da Grama Mato-grosso (Paspalum notatum Flüegge), mantida com altura de dossel mínimo de cinco centímetros. As principais plantas invasoras observadas durante o período experimental foram: Dorme-dorme (Mimosa invisa Mart), Assa peixe (Vernonia sp.), Guanxuma (Sida rhombifolia), Picão preto/branco (Bidens pilosa/Galinsoga parviflora), Falsa-serralha (Emilia sonchifolia), Falsa erva de rato (Asclepias bicolor Moench.), Juá (Ziziphus joazeiro Mart).

Os animais foram distribuídos em cinco tratamentos experimentais: pasto limpo sem fornecimento de suplemento concentrado (PLSC); pasto sujo sem fornecimento de suplemento concentrado (PSSC); pasto limpo com fornecimento de suplemento concentrado (PLCC); pasto sujo com fornecimento de suplemento concentrado (PSCC) e livre acesso aos pastos sem fornecimento de suplemento concentrado (LAPSC). A quantidade de suplemento concentrado fornecido a cada animal foi de $0,5 \%$ do PV/dia, fornecida duas vezes ao dia às $8 \mathrm{~h} 00$ e às $13 \mathrm{~h} 30$ em cochos cobertos dentro do respectivo piquete. Os animais foram pesados no início e no final de cada período experimental para adequação da dieta.

$\mathrm{O}$ delineamento experimental foi em quadrado latino $5 \times 5$ períodos, com cada período com duração de 12 dias, sendo 10 dias de adaptação às dietas e à iluminação artificial noturna e os dois últimos dias para coleta de dados. As variáveis fisiológicas foram coletadas no $11^{\circ}$ dia e $o$ comportamento ingestivo avaliado no $12^{\circ}$ dia de coleta.

O comportamento ingestivo dos animais foi mensurado por meio de observação visual no final de cada período experimental em intervalos de dez 
minutos, durante 24 horas, para determinação do tempo despendido em alimentação, ruminação e ócio (JOOHNSON \& COMBS, 1991). Os dados de velocidade do vento, temperatura de ponto de orvalho, temperatura do ar e umidade relativa foram coletadas por um termoanemômetro e o calor radiante foi registrado utilizando o globo de Vernon de $0,15 \mathrm{~m}$ de diâmetro exposto ao sol.

As variáveis climáticas foram coletadas duas vezes por semana, em intervalos de uma hora, durante 24 horas. A partir dos dados de temperatura e umidade do ar, foi calculado o índice de temperatura e umidade (ITU), mediante a fórmula referida por KELLY \& BOND (1971):

$$
I T U=T b s-0,55(1-U R)(T b s-58)
$$

(Eq. 1)

sendo:

Tbs = temperatura de bulbo seco, $\left({ }^{\circ} \mathrm{F}\right)$,

$\mathrm{UR}=$ umidade relativa expressa como um valor decimal.

Os dados de ITU foram interpretados segundo AZEVEDO et al. (2005), em que: ITU inferior a 70 representa ausência de estresse; entre 70 e 72, alerta, alcançando o nível crítico; entre 72 e 78, acima do ponto crítico; entre 78 a 82 , perigo, e superior a 82 , emergência. A radiação térmica é um importante fator ambiental, que tem seu valor elevado quando os animais são mantidos em regime de pastejo. Desta forma foi calculado o índice de temperatura do globo e umidade (ITGU), a partir dos dados de temperatura do globo de Vernon $\left({ }^{\circ} \mathrm{C}\right)$ e temperatura de ponto de orvalho, mediante a fórmula de BUFFINGTON et al. (1981):

$I T G U=T g+0,36 T p o+41,5$

(Eq. 2)

em que:

$\mathrm{Tg}=$ temperatura do globo de Vernon, ${ }^{\circ} \mathrm{C}$

Tpo $=$ temperatura de ponto de orvalho.

A temperatura retal (TR) individual foi medida por um termômetro clínico digital. A frequência cardíaca (FC) foi medida através de estetoscópio, por uma só pessoa, em todos os animais, pelo lado esquerdo do animal, próximo ao osso xifóide, contando-se os batimentos ocorridos em um período de 15 segundos, multiplicando-se o valor obtido por quatro. A frequência respiratória (FR) foi obtida pela contagem dos movimentos do flanco dos animais, com o auxílio de um cronômetro por um período de 10 segundos, sendo o resultado multiplicado por 6 para obtenção em minutos. As variáveis foram submetidas à análise de variância e as médias foram comparadas pelo teste de Student Newman Keulls (SNK), a 5\% de probabilidade, utilizando-se o programa SAEG 9.1 - Sistema de Análises Estatísticas e Genéticas (UFV, 2007).

\section{RESULTADOS E DISCUSSÃO}

A temperatura do ar média durante o experimento foi de $23,39^{\circ} \mathrm{C}$, com máxima de $30,5^{\circ} \mathrm{C}$ e mínima de $16,4^{\circ} \mathrm{C}$. A umidade relativa do ar variou entre $88 \%$ e $35 \%$. Os valores mínimos de umidade relativa coincidiram com os valores máximos de temperatura do globo negro, podendo indicar uma relação inversamente proporcional entre a carga de energia radiante do ambiente com os níveis de umidade do ar. Foram observados valores de ITU de 71 e 78 , dentro da faixa crítica para bovinos, durante grande parte do período de avaliação, (10h00 às $21 \mathrm{~h} 00$ ), indicando que nesses horários críticos os animais estavam sujeitos ao estresse térmico. De acordo com SILVA et al. (2008), o índice de temperatura e umidade (ITU) tem sido amplamente utilizado para avaliar ambientes para bovinocultura em regiões tropicais e valores críticos do ambiente obtidos pelo índice comprometem o comportamento e a produção animal.

Segundo BAETA \& SOUZA (2010), os valores de ITGU até 74 indicam uma condição de conforto térmico para os bovinos anelorados; entre 75 e 78, a situação é de alerta, de 79 a 84 caracteriza perigo e, acima disso, depara-se com situação de emergência. Foram observados valores de ITGU acima da faixa de perigo (emergência), entre as 08h00 e às 17h00, atingindo o valor máximo de 94,40 . Porém, de maneira semelhante ao verificado para ITU, os animais demonstraram desconforto térmico nos horários de emergência, buscando sombra para evitar a radiação solar direta. Nos horários subsequentes, os valores de ITGU permaneceram abaixo dos níveis de alerta para os animais. Os valores médios da temperatura retal (TR), frequência cardíaca (FC) e frequência respiratória (FR) dos animais encontram-se descritos na Tabela 1.

$\mathrm{O}$ aumento da frequência respiratória e da ofegação são mecanismos fisiológicos importantes para a dissipação de calor nessa espécie. No entanto, esses mecanismos de calor demandam energia, resultando no aumento de mantença diária de bovinos de 7 para $25 \%$, o que também resulta em produção de calor (COLUMBIANO, 2007). Como defesa ao desconforto térmico, os bovinos recorrem a mecanismos adaptativos fisiológicos de perda de calor corporal para tentar evitar a hipertermia. Assim, aumentam a frequência respiratória apresentando taquipneia, como complemento ao aumento da taxa de sudorese, constituindo, ambos, importantes meios de perda de calor do corpo por evaporação. Em condições normais de temperatura, as vacas cruzadas apresentam frequência respiratória 
em torno de 18 a 28 movimentos por minuto, a partir de $26^{\circ} \mathrm{C}$ os movimentos começam a aumentar. Em temperatura de $31^{\circ} \mathrm{C}$, apresentam em média 68 movimentos por minuto. Até 60 movimentos os animais não apresentam ainda sinais de estresse. Ultrapassando 120 movimentos, já refletem carga excessiva de calor e acima de 160 faz-se necessário adotar medidas emergenciais (BACCARI, 2001).

TABELA 1 - Valores médios de temperatura retal (TR), frequência cardíaca (FC) e frequência respiratória (FR)

\begin{tabular}{lccc}
\hline Tratamentos & $\mathrm{TR}\left({ }^{\circ} \mathrm{C}\right)$ & $\mathrm{FC}(\mathrm{bat} / \mathrm{min})$ & $\mathrm{FR}(\mathrm{mov} . / \mathrm{min})$ \\
\hline PLSC & 37,80 & 122,00 & 47,50 \\
PSSC & 38,10 & 124,00 & 48,40 \\
PLCC & 37,90 & 130,00 & 42,00 \\
PSCC & 38,10 & 131,00 & 43,50 \\
LAPSC & 37,90 & 126,00 & 45,40 \\
CV $(\%)$ & 0,58 & 7,84 & 22,40 \\
\hline
\end{tabular}

PLSC - Pasto limpo sem fornecimento de suplemento concentrado PSSC - Pasto sujo sem fornecimento de suplemento concentrado PLCC - Pasto limpo com fornecimento de suplemento concentrado PSCC - Pasto sujo com fornecimento de suplemento concentrado LAPSC - Livre acesso aos pastos sem fornecimento de suplemento concentrado
Os valores médios encontrados de frequência cardíaca e respiratória (126 batimentos/minuto e 45,36 movimentos/minuto, respectivamente) não foram influenciados pelos diferentes tratamentos. A Tabela 2 apresenta os dados de tempo de alimentação (TAL), tempo de ruminação (TRU), tempo de ócio (TOCIO), tempo de ingestão de água (TAGUA), tempo de ruminação em pé e deitado, tempo de ócio em pé e deitado, número de refeições diárias (Nref) e número de períodos de ruminação (Nrum), com seus respectivos coeficientes de variação em função dos diferentes tratamentos.

Não foram verificadas diferenças significativas para os tempos de alimentação, ócio e água, com médias de 9,03, 6,17 e 0,50 horas/dia, respectivamente. Apesar do tempo despendido em ócio não ter apresentado diferenças entre os tratamentos, os animais mantidos em pastagem sem controle de plantas invasoras apresentaram um valor numericamente menor de ócio, isso provavelmente ocorre devido a um maior tempo gasto na procura por alimentos. O tempo de ócio com o animal em pé ocorreu preferencialmente durante o dia e o ócio noturno foi caracterizado principalmente pelos animais deitados.

TABELA 2. Variáveis comportamentais em relação aos diferentes tratamentos

\begin{tabular}{|c|c|c|c|c|c|c|}
\hline \multirow{2}{*}{ Variáveis } & \multicolumn{5}{|c|}{ Tratamentos } & \multirow[b]{2}{*}{$\mathrm{CV}(\%)$} \\
\hline & PLSC & PSSC & PLCC & PSCC & LAPSC & \\
\hline TAL (h/dia) & 9,2 & 9,1 & 9,1 & 8,7 & 9,03 & 7,21 \\
\hline TRU (h/dia) & $7,60^{\mathrm{b}}$ & $8,60^{\mathrm{a}}$ & $7,80^{\mathrm{b}}$ & $8,90^{\mathrm{a}}$ & $8,39^{\mathrm{ab}}$ & 5,52 \\
\hline TOCIO (h/dia) & 6,8 & 5,6 & 6,6 & 5,7 & 6,14 & 11,24 \\
\hline TAGUA (h/dia) & 0,5 & 0,49 & 0,51 & 0,5 & 0,51 & 1,32 \\
\hline TRU Pé (h/dia) & 0,82 & 1,01 & 0,8 & 1,03 & 0,91 & 22,12 \\
\hline TRU Deitado (h/dia) & $6,81^{\mathrm{c}}$ & $7,84^{\mathrm{a}}$ & $7,09^{\mathrm{bc}}$ & $7,95^{\mathrm{a}}$ & $7,46^{\mathrm{ab}}$ & 5,21 \\
\hline TOCIO Pé (h/dia) & $2,56^{\mathrm{a}}$ & $1,12^{\mathrm{c}}$ & $1,99^{\mathrm{b}}$ & $1,09^{\mathrm{c}}$ & $2,33^{\mathrm{a}}$ & 26,76 \\
\hline TOCIO Deitado (h/dia) & $4,38^{\mathrm{b}}$ & $4,63^{\mathrm{b}}$ & $4,71^{\mathrm{a}}$ & $4,49^{\mathrm{b}}$ & $3,78^{\mathrm{c}}$ & 20,85 \\
\hline $\operatorname{Nref}\left(n^{\circ} / \mathrm{dia}\right)$ & 8,75 & 8,5 & 11,5 & 8,25 & 9,24 & 20,37 \\
\hline Nrum (n\%dia) & 15,25 & 13,75 & 13,75 & 12,52 & 13,63 & 10,91 \\
\hline
\end{tabular}

Médias seguidas de letras diferentes na linha diferem $(\mathrm{p}<0,05)$ pelo teste Student-Newman-Keuls

PLSC - Pasto limpo sem fornecimento de suplemento concentrado

PSSC - Pasto sujo sem fornecimento de suplemento concentrado

PLCC - Pasto limpo com fornecimento de suplemento concentrado

PSCC - Pasto sujo com fornecimento de suplemento concentrado

LAPSC - Livre acesso aos pastos sem fornecimento de suplemento concentrado

BRÂNCIO et al. (2003) relataram tempos de pastejo de bovinos, em termos médios, entre 8,3 e 11,3 horas diárias, avaliando o comportamento ingestivo de bezerros nelore com $150 \mathrm{~kg}$ de peso vivo em pastagem de capim-tanzânia, com e sem adubação. ZANINE et al. (2007), trabalhando com bezerros, observaram que os animais pastejaram mais tempo no início da manhã e final da tarde, no pasto de Brachiaria brizantha.

O tempo de ruminação foi significativamente 
maior para os animais mantidos em piquetes com presença de plantas invasoras com e sem suplementação concentrada, com valores de 8,60 e 8,90 horas/dia, respectivamente, quando comparados aos animais em piquetes limpos, 7,60 e 7,80 horas/dia, respectivamente. Valores semelhantes foram relatados no trabalho de MENDONÇA et al. (2004), com média de 7,71 horas/dia. A ruminação ocorreu preferencialmente com o animal deitado em todos os tratamentos, tendo os maiores tempos para os tratamentos PSCC e PSSC com valores de 7,95 e 7,84 horas/dia, respectivamente, e o valor mínimo para o tratamento PLSC com média de 6,81 horas/dia.
O número de refeições e número de períodos de ruminação não foram alterados pelos diferentes tratamentos, com valores médios de 9,25 e 13,78 $\mathrm{n} \%$ dia, respectivamente. BURGUER et al. (2000), trabalhando com dietas com níveis crescentes de concentrado, observaram um maior número de refeições, com média de 14,80. Na Figura 1 observase que, entre 8 e $20 \mathrm{~h}$, foi registrado o maior tempo despendido para consumo de alimento $(83,42 \%$ do consumo total de alimento diário). Uma refeição é definida por uma longa sequência de pastejo. Quando ela se interrompe por vários minutos, a refeição anterior se define, e a próxima iniciará tão logo o animal inicie uma nova sequência.

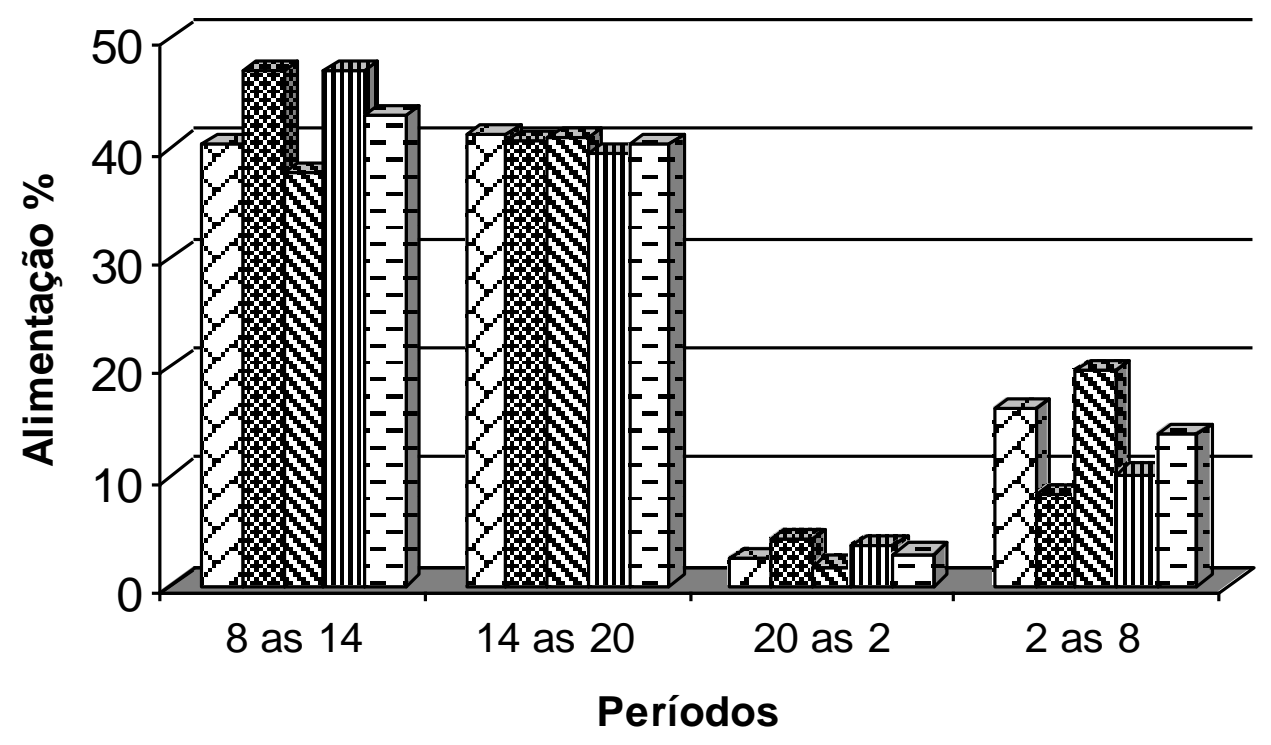

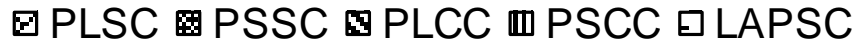

FIGURA 1. Padrão do comportamento ingestivo dos tempos diários despendidos em alimentação, para cada tratamento, em função de quatro períodos de 6 horas.

PLSC - Pasto limpo sem fornecimento de suplemento concentrado

PSSC - Pasto sujo sem fornecimento de suplemento concentrado

PLCC - Pasto limpo com fornecimento de suplemento concentrado

PSCC - Pasto sujo com fornecimento de suplemento concentrado

LAPSC - Livre acesso aos pastos sem fornecimento de suplemento concentrado

O tempo de consumo de alimento durante o período das 20 às $8 \mathrm{~h}$ foi de apenas $16,58 \%$ e a atividade de ruminação ocorreu preferencialmente durante a noite, horário em que a temperatura foi mais amena, em torno de $19,9^{\circ} \mathrm{C}$, com $80,86 \%$ da ruminação ocorrendo entre 20 e 8 h. BALOCCHI et al. (2002) utilizaram 12 bovinos para avaliar a suplementação com dois tipos de concentrado (polpa de beterraba e cereal) sobre o tempo de pastejo, tempo de ruminação e tempo para outras atividades, além do consumo de pasto, consumo total de matéria seca. A suplementação alterou o comportamento de 
pastejo, diminuindo o pastejo total e diurno; aumentou a ruminação diurna e diminuiu a ruminação noturna e diminuiu o número de bocados. Não houve diferença entre os tipos de concentrado. $\mathrm{O}$ consumo de matéria seca total aumentou e o consumo de pasto diminuiu com a suplementação, sem diferença entre os concentrados.
O padrão diário da atividade de ruminação, exposto na Figura 2, apresentou valores elevados 10 horas após o fornecimento da alimentação (20 às 2 h), mantendo-se em plena atividade durante 12 horas subsequentes.

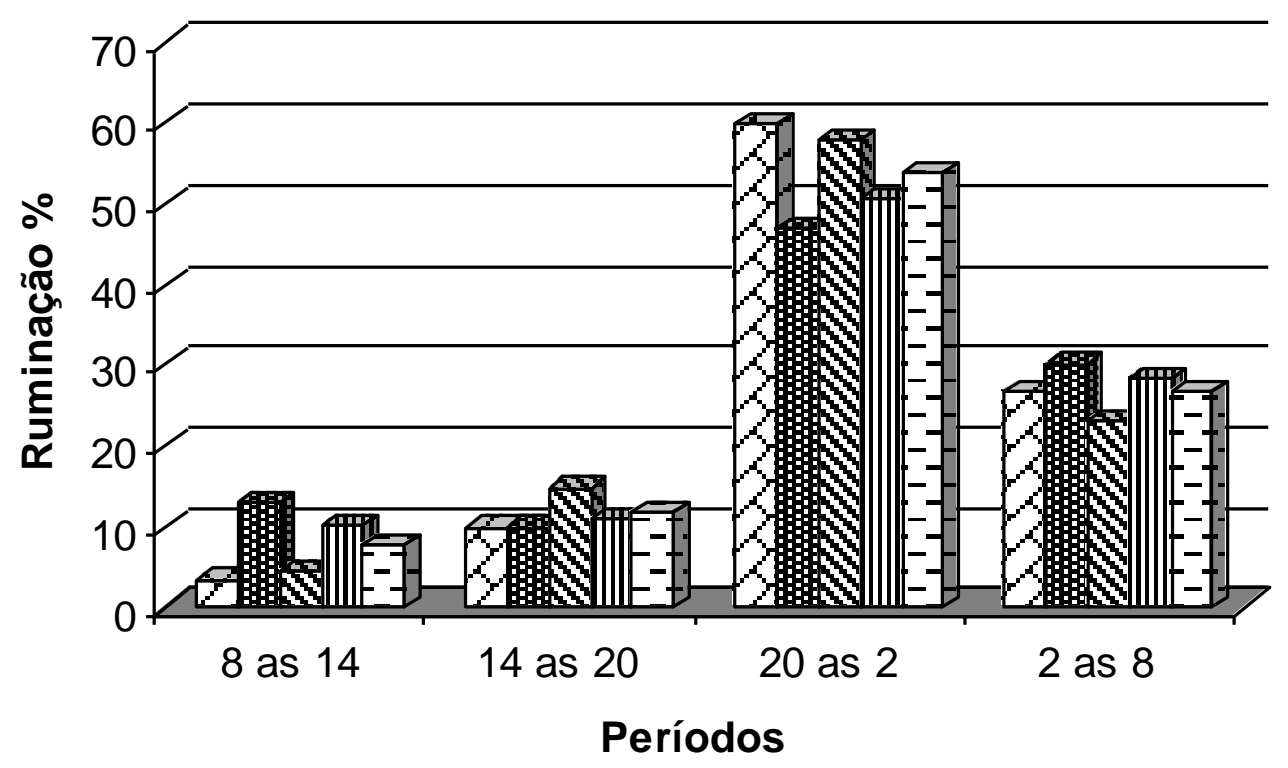

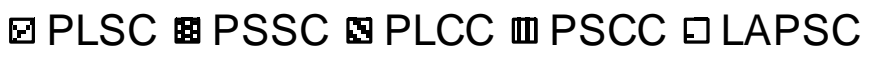

FIGURA 2. Padrão do comportamento ingestivo dos tempos diários despendidos em ruminação, para cada tratamento, em função de quatro períodos de 6 horas.

PLSC - Pasto limpo sem fornecimento de suplemento concentrado

PSSC - Pasto sujo sem fornecimento de suplemento concentrado

PLCC - Pasto limpo com fornecimento de suplemento concentrado

PSCC - Pasto sujo com fornecimento de suplemento concentrado

LAPSC - Livre acesso aos pastos sem fornecimento de suplemento concentrado

Nota-se uma variação da posição para ruminação dos animais durante o dia e a noite. Durante a noite, a ruminação ocorre $87,69 \%$ com os animais deitados, o que pode ter relação com o maior conforto térmico durante esse período. Durante o dia, $74,17 \%$ da ruminação ocorre em pé, provavelmente devido à maior temperatura ambiental e ao aumento das atividades sociais dos animais. $\mathrm{O}$ ócio foi definido pelo tempo em que os animais não estavam consumindo alimento, ruminando ou bebendo água. O tempo despendido em ócio foi semelhante para todos os tratamentos testados, não sendo observadas diferenças estatísticas. Entretanto, observou-se um padrão de comportamento para todos esses tratamentos, em que a atividade de ócio foi similar para os períodos compreendendo o horário das 8 às 2 horas e o maior tempo despendido para o ócio $41,24 \%$ no período das 2 às 8 horas. Esse padrão comportamental pode ser devido ao descanso dos animais ser predominante nesse período do dia. No período das 2 às 8 horas, os animais permaneceram $46,68 \%$ deitados. Durante o dia, o ócio ocorreu preferencialmente com o animal em pé, provavelmente devido a fatores evolutivos, pois os animais permanecem em estado de alerta contra predadores durante a procura por alimentos.

Os bovinos tendem a minimizar o tempo de pastejo como estratégia de ingestão de forragem e essa pode ser uma herança evolutiva, visto que funcionaria como estratégia de escape à predação 
(RUTTER et al., 2002). ZANINE et al. (2007), trabalhando com bezerros, observou que os maiores tempos de ruminação ocorreram no início e no final da noite.

O consumo de água ocorreu durante o dia, no horário de maior consumo alimentar e maiores temperaturas ambientais, não sendo detectada qualquer atividade de consumo de água durante o período noturno. O número de sítios por minuto e número de passos por minuto, apresentados na Tabela 3, foram influenciados $(\mathrm{P}<0,05)$ pela presença de invasoras na pastagem.

TABELA 3 - Valores médios do número de sítio de pastejo ( $\mathrm{N}^{\circ}$ Sítio/minuto), número de bocados $\left(\mathrm{N}^{\circ}\right.$ bocado/minuto) e número de passos $\left(\mathrm{N}^{\circ}\right.$ passos/minuto), para cada tratamento

\begin{tabular}{lccc}
\hline Tratamento & $\begin{array}{c}\mathrm{N}^{\mathrm{o}} \\
\text { Sítio/min }\end{array}$ & $\begin{array}{c}\mathrm{N}^{\mathrm{o}} \\
\text { bocado/min }\end{array}$ & $\begin{array}{c}\mathrm{N}^{\mathrm{o}} \\
\text { passos/min }\end{array}$ \\
\hline PLSC & $2,84^{\mathrm{a}}$ & 27,36 & $6,08^{\mathrm{a}}$ \\
PSSC & $4,24^{\mathrm{b}}$ & 23,52 & $16,84^{\mathrm{b}}$ \\
PLCC & $2,76^{\mathrm{a}}$ & 24,23 & $5,62^{\mathrm{a}}$ \\
PSCC & $5,32^{\mathrm{b}}$ & 23,44 & $14,58^{\mathrm{b}}$ \\
LAPSC & $2,57^{\mathrm{a}}$ & 24,11 & $7,89^{\mathrm{a}}$ \\
CV \% & 15,13 & 6,84 & 16,21 \\
\hline
\end{tabular}

Médias seguidas de letras diferentes na coluna diferem $(\mathrm{p}<0,05)$ pelo teste de Tukey.

PLSC - Pasto limpo sem fornecimento de suplemento concentrado PSSC - Pasto sujo sem fornecimento de suplemento concentrado PLCC - Pasto limpo com fornecimento de suplemento concentrado PSCC - Pasto sujo com fornecimento de suplemento concentrado LAPSC - Livre acesso aos pastos sem fornecimento de suplemento concentrado

Nos tratamentos em que os animais estavam mantidos em pasto livre de invasoras, PLSC e PLCC, o número de sítios de pastejo por minuto foi de 2,84 e 2,76, respectivamente, valores menores do que os estabelecidos quando os animais estavam mantidos em pasto com alto grau de invasoras, PSSC $(4,24)$ e PSCC $(5,32)$. Animais mantidos em piquetes com invasores locomoveram-se mais em busca de alimento que os animais mantidos em piquetes limpos, provavelmente devido à elevada contaminação da pastagem por plantas invasoras que dificultavam o pastejo. Essa maior locomoção para consumo de alimento no piquete sujo é observada quando se compara o número de passos por minuto realizados pelos animais.

Em piquete limpo, PLSC e PLCC, o número de passos por minuto foi de 6,08 e 5,62, respectivamente, enquanto para os tratamentos PSSC e PSCC foi de 16,84 e 14,58. Esses resultados comprovam que animais mantidos em piquetes com invasoras necessitam locomover-se mais que animais mantidos em piquetes limpos, podendo ocasionar uma maior demanda energética para movimentação, reduzindo a produtividade animal.

\section{CONCLUSÕES}

Não foram verificadas diferenças significativas para os tempos de alimentação, ócio e água. A ruminação ocorreu preferencialmente com o animal deitado em todos os tratamentos, tendo os maiores tempos para os tratamentos PSCC e PSSC.

O tempo de ócio com o animal em pé ocorreu preferencialmente durante o dia e o ócio noturno foi caracterizado principalmente pelos animais deitados. O tempo despendido em ócio foi semelhante para todos os tratamentos testados, não sendo observadas diferenças estatísticas, porém observou-se um padrão de comportamento, em que a atividade de ócio foi similar para os períodos compreendendo o horário das 8 às 2 horas e o maior tempo despendido para o ócio no período das 2 às 8 horas.

Durante o dia, o ócio ocorreu preferencialmente com o animal em pé, provavelmente devido a fatores evolutivos, uma vez que os animais permanecem em estado de alerta contra predadores durante a procura por alimentos.

Para os animais mantidos em piquetes limpos, PLSC e PLCC, registraram-se menores números de passos por minuto em comparação com os tratamentos PSSC e PSCC. Esses resultados demonstram que animais mantidos em piquetes com invasoras necessitam locomover-se mais que animais mantidos em piquetes limpos. Isso pode ocasionar uma maior demanda energética para movimentação, reduzindo a produtividade animal.

\section{REFERÊNCIAS}

AZEVEDO, M.; PIRES, M.F.A.; SATURNINO, H.M; LANA, A.M.Q. Estimativa de níveis críticos superiores do índice de temperatura e umidade para vacas leiteiras $1 / 2$, 3/4, 7/8 holandes-zebu em lactação. Revista Brasileira de Zootecnia, v.34, n.6, p.2000-2008, 2005.

BACCARI JR., F. Manejo ambiental da vaca leiteira em clima quente. Londrina: UEL, 2001. 142p.

BAETA, F. C.; SOUZA, C. F. Ambiência em edificações rurais - conforto animal. Viçosa: Editora da Universidade Federal de Viçosa. 2010. 269p.

BALOCCHI, O.L.; PULIDO, R.F.; FERNÀNDEZ, J.V. Comportamiento de vacas lecheras en pastoreo con y sin suplementación con concentrado. Agricultura Técnica, v.62, 87-98, 2002. 
BRÂNCIO, P.A.; EUCLIDES, V.P.B.; NASCIMENTO JÚNIOR， D.; FONSECA， D.M.; ALMEIDA， G.; MACEDO, M.C.M.; BARBOSA, R.A.. Avaliação de três cultivares de Panicum maximum Jacq. sob pastejo: comportamento ingestivo de bovinos. Revista Brasileira de Zootecnia. v. 32, n. 5, p.1045-1046, 2003.

BUFFINGTON, D. E. COLLAZO-AROCHO, A.; CANTON, G.H.; PITT, D. Black globe-humidity index (BGHI) as comfort equation for dairy cows. Transactions of the ASAE, v.24, p.711-714, 1981.

BURGÜER, P.J.; PEREIRA, J.C.; QUEIROZ, A.C. Comportamento ingestivo em bezerros holandeses alimentados com dietas contendo diferentes níveis de concentrado. Revista Brasileira de Zootecnia, v.29, n.1, p.236-242, 2000 .

COLUMBIANO, V.S. Identificação de QLT nos cromossomos 10, 11 e 12 associados ao estresse calórico em bovinos. 2007. 60f. Dissertação (Mestrado em Genética e Melhoramento Animal) - Universidade Federal de Viçosa, Viçosa. Disponível em http://www.tede.ufv.br/tedesimplificado/tde_arquivos/22/ TDE-2007-07-09T101230Z-

613/Publico/texto\%20completo.pdf, acesso em julho de 2012.

FISCHER, V.; DESWYSEN, A.G.; DUTILLEUL, P. Padrões da distribuição nictemeral do comportamento ingestivo de vacas leiteiras, ao inicio e ao final da lactação, alimentadas com dieta à base de silagem de milho. Revista Brasileira de Zootecnia, v.31, n.5, p.2129-2138, 2002.

FISCHER, V.; DUTILlEUL, P.; DESWYSEN, A.G. Aplicação de probabilidades de transição de estado dependentes do tempo na análise quantitativa do comportamento ingestivo de ovinos - Parte I. Revista Brasileira de Zootecnia, v.29, n.6, p.1811-1820, 2000.

JOHNSON, T. R., COMBS, D. K. Effects of prepartum diete, inert rumen bulk, and dietary polyethylene glycol on dry matter intake of lactating dairy cows. Journal of Dairy Science, v.74, n.3, p.933-944, 1991.

KELLY, C.F., BOND, T.E. Bioclimatic factors and their measurement. In: National Academy of Sciences. A guide to environmental research on animals. Washington: IAS, 1971. 76p.

MENDONÇA, S.S.; CAMPOS, J.M.S.; VALADARES
FILHO, S.C. Comportamento ingestivo de vacas leiteiras alimentadas com dietas à base de cana-de-açúcar ou silagem de milho. Revista Brasileira de Zootecnia. v.33, n.3, p.729-737, 2004.

PALHANO, A.L.; CARVALHO,P.C.F.;DITTRICH, J.R.; MORAES, A.; SILVA, S.C.; MONTEIRO,A.L.G.; Características do processo de ingestão de forragem por novilhas holandesas em pastagens de capim-mombaça. Revista Brasileira de Zootecnia. v.36, n.4, p.1014-1021, 2007.

PARDO, R.M.P.; FISCHER, V.; BALBINOTTI, M.; MORENO, C.B.; FERREIRA, E.X.; VINHA, R.J.; MONK, P.L. Comportamento ingestivo diurno de novilhos em pastejo submetidos a níveis crescentes de suplementação energética. Revista Brasileira de Zootecnia. v. 32, n. 6, p. 1408-1418, 2003.

RUTTER, S. M.; ORR, R. J.; PENNING, P. D.; YARROW, N, H,; CHAMPION, R. A. Ingestive behaviour of heifers grazing monocultures of ryegrass or white clover. Applied Animal Behavior Science. v. 76, p. 1-9, 2002.

SILVA, E. C. L. ; MODESTO, E. C. ; AZEVEDO, M. ; FERREIRA, M. A. ; DUBEUX JUNIOR, J. C. B. ; SCHULER, A.R.P . Efeitos da disponibilidade de sombra sobre o desempenho, atividades comportamentais e parâmetros fisiológicos de vacas da raça Pitangueiras. Acta Scientiarum. Animal Sciences, v. 31, p. 295-302, 2009.

SILVA, R.G. Biofísica ambiental. Os animais e seu ambiente. 1.ed. Jaboticabal: Funep, 2008. 393p.

UNIVERSIDADE FEDERAL DE VIÇOSA - UFV. SAEG - Sistema para Análises Estatísticas. Versão 9.1. Viçosa, 2007.

ZANINE, A.M.; SANTOS, E.M.; PARENTE, H.N.; FERREIRA, D.J.; ALMEIDA, F.Q.A. Comportamento ingestivo de bezerros em pastos de Brachiaria brizantha e Brachiaria decumbens. Revista Ciência Rural, Santa Maria, RS, 2005.

ZANINE, A.M.; SANTOS, E.M.; PARENTE, H.N.; FERREIRA, D.J.; CECON, P.R. Hábito de pastejo de vacas lactantes Holandês $x$ Zebu em pastagens de Brachiaria brizantha e Brachiaria decumbens. Arquivo Brasileiro de Medicina Veterinária e Zootecnia, v.59, n.1, p.175-181, 2007. 